\title{
ANÁLISIS DE LA COSIFICACIÓN DE LA MUJER DESDE UNA PERSPECTIVA DE GÉNERO
}

\author{
Claudia Isbela López ${ }^{1}$, Elvia Elizabeth Gómez, Sandy Justiniano \\ Facultad de Ciencias Administrativas y Sociales \\ Universidad Tecnológica Centroamericana, San Pedro Sula, Honduras \\ (Enviado: Octubre, 2017 / Aceptado: Agosto, 2018)
}

\begin{abstract}
Resumen
Cada año durante las celebraciones de las fiestas patrias, los medios de comunicación enfocan sus lentes hacia las presentaciones artísticas realizadas por las diferentes instituciones educativas, en las cuales sobresalen los grupos de palillonas con sus trajes coloridos y sus movimientos al ritmo de las "bandas de guerra." Pero más allá de exaltar sus habilidades artísticas, los medios se centran en los atributos físicos de ellas, violentando claramente sus derechos al convertirlas en objetos sexuales; por lo que lejos de ser un tributo a la patria, estos desfiles evidencian la cosificación de la mujer, que es vista y tratada como un objeto. Desde la perspectiva de género, debemos considerar que esta situación está íntimamente relacionada con la influencia de los roles tradicionales atribuidos a las mujeres en nuestra sociedad, en los cuales lo más importante es la apariencia física, enmarcada en estereotipos que no considera un proceso de formación integral y de inclusión social. De igual forma, observamos cómo a lo largo del territorio nacional se realizan elecciones de reinas infantiles, en las cuales las niñas son vestidas con atuendos que no son acordes a su edad, lo que vulnera sus derechos pues son expuestas a estereotipos.
\end{abstract}

Palabras clave: Derechos humanos, cosificación, estereotipos.

\begin{abstract}
Every year during the celebrations of the independence day, the media focus their lenses to the artistic presentation carried out by the different educational institutions, in which outstand groups of "palillonas" with their colorful costumes and their movements to the beat of the "war bands". But rather than exalting her artistic skills, focusing on their physical attributes, clearly violating their right by converting them into sex objects, so far from being a tribute to the nation, these parades demonstrate the objectification of women that is seen and treated as an object. From the gender perspective we should consider that this situation is closely related to the influence of the traditional roles attributed to women in our society, according to which, the most important is the physical appearance, considered under stereotypes that do not consider a process of integral education and social inclusion. By the same way, we observed throughout the country the practice of child queen elections, where the girls are dressed in outfits that are not in line with their age, that violates their rights because they are exposed to stereotypes. Key words: Humans rights, objectification, stereotypes.
\end{abstract}

\footnotetext{
$\overline{{ }^{1} \text { Autor para correspondencia. Email: isbella.lopez@unitec.edu }}$
} 


\section{Introducción}

La sociedad occidental, entre las cuales la hondureña no es la excepción, mantiene en su imaginario una serie de estereotipos por razón de género. El estereotipo objeto de razonamiento en este estudio es el que medida del éxito en la vida de una mujer está muy relacionada y/o asociada a su apariencia o atributos físicos más que a sus capacidades intelectuales. La sociedad occidental ha supervalorado la importancia de la belleza exterior donde se ha creado un ideal femenino en el que las niñas/mujeres son sumergidas por un bombardeo de los medios de comunicación de la noción ideal de la belleza, por lo cual la sociedad ha determinado un rol específico de la mujer siendo vista como objeto de belleza, objeto de procreación u objeto de placer para el hombre.

Determinada por una noción ideal del éxito, niñas y mujeres son expuestas a diario a ser cosificadas y consecuentemente discriminadas. En una sociedad que es integrada por padres, tutores legales, autoridades, instituciones educativas, medios de comunicación y el Estado, dicha problemática se ha naturalizado y ha recibido el visto bueno.

Cada año se llevan a cabo en nuestro país dos actividades que son el objeto de la presente investigación; los reinados infantiles de belleza y las fiestas patrias. En el caso de los cuadros de palillonas, las niñas son expuestas a ser cosificadas y a generarles una noción errónea del éxito y de la belleza, sin tomar en consideración las repercusiones que esto puede tener en la vida de las niñas/mujeres y dentro de esto, la violación a sus derechos humanos. En dichas actividades las niñas/mujeres son sexualizadas y se ven frente a un aceleramiento de las etapas propias de la vida donde son afectadas tanto física, psicológica y moralmente, lo que se avala según lo planteado en el Reporte de la Fuerza de Tarea de la Asociación Americana de Psicología sobre la Sexualización de las Niñas (2007), que analiza la influencia de la vestimenta en la sexualización de las niñas.

El Estado se encuentra en la obligación de velar por el cumplimiento de los convenios internacionales que Honduras ha ratificado, así como algunos artículos de sus leyes como la Constitución de la República y el Código de la Niñez en los cuales se vela para eliminar todas las formas de discriminación.

En la actualidad, el Estado no ha cumplido a cabalidad los deberes adquiridos en dichas convenciones lo que conlleva a un incremento de las diversas problemáticas que aquejan al país, entre ellas el incremento en los índices de femicidios, lo que ha llevado a Honduras a convertirse en el peor país para ser mujer, tal y como indica el Observatorio de Igualdad de Género de América Latina y el Caribe en su sitio web, en el apartado sobre Autonomía física, femicidio "Honduras sigue siendo, para todos los años de la serie histórica, el país de la región con el mayor número total de femicidios (466 en el 2016), alcanzando una preocupante tasa de un 10.2 femicidios por cada 100.000 mujeres” (Observatorio de Igualdad de Género CEPAL, 2017).

Los medios de comunicación se vuelven cruciales en la transmisión de información, y en los casos tipo abordados en la presente investigación podemos señalar que realizan una serie de acciones tendientes a utilizar estos eventos para la transmisión de frases inadecuadas y de alto contenido sexual, fotografías de las niñas/mujeres generando acoso sexual y cosificándolas, lo 
cual en este estudio se vuelve crucial para identificar las violaciones y caracterizar la cosificación de la niña/mujer a partir de los dos casos tipos: las palillonas de los desfiles patrios y los reinados infantiles.

En la actualidad dichos concursos han intensificado el uso de las redes sociales donde los padres de familia, tutores y el Estado se vuelven cómplices del proceso de cosificación y sexualización al que las niñas son expuestas al participar en este tipo de actividades, pues no logran dimensionar las repercusiones de los mismos en el desarrollo psico-social de la niña/mujer, afianzando de alguna forma el machismo predominante en nuestro país. Los padres, tutores, familiares, encargados, medios de comunicación exhiben en una ventana pública a través de diferentes plataformas a las niñas/mujeres a través de la publicación de imágenes con vestimenta inadecuada y poses consideradas sexys que las someten a una adultez innecesaria.

Al ser del dominio público, dichas imágenes pueden ser utilizadas para cualquier fin ya sea en el ámbito nacional o internacional e inclusive desembocar en casos de pedofilia, pornografía infantil y trata de personas. Unido a lo anterior, estos cánones de belleza afianzados por los medios de comunicación y la sociedad misma contribuyen sustancialmente a incrementar problemas relacionados con el ámbito de la salud física y emocional como la anorexia, bulimia y depresión. El no encajar en dichos patrones hace que la niña/mujer se desvalorice e interiorice sentimientos negativos que a la larga le llevan a aceptar como algo natural el hecho de ser objeto de violencia sexual, física y emocional.

Podemos ver en las noticias de los diarios nacionales cómo ha ido incrementando el femicidio, ligado en su mayoría a la violencia ejercida por la pareja. También el incremento en los casos de embarazo adolescente en donde la mayoría son víctimas de abuso por parte de miembros de su misma familia, ante la vista y paciencia de un Estado que no ha cumplido con su obligación de protegerles y de una sociedad que se vuelve cómplice del afianzamiento de estos patrones.

Tomando en cuenta las consideraciones anteriores, el objetivo general del estudio es presentar desde la perspectiva de género la cosificación de la niña/mujer en función de dos casos tipos considerando la violación de sus derechos humanos: las palillonas de los desfiles patrios y los reinados infantiles. Para lograr el objetivo propuesto, se plantean varios objetivos específicos: 1) caracterizar la cosificación de la niña/mujer en la sociedad hondureña a partir del abordaje de los dos casos tipos: las palillonas de los desfiles patrios y los reinados infantiles; 2) identificar las violaciones de los derechos de la niña/mujer a partir del abordaje de los dos casos tipos: las palillonas de los desfiles patrios y los reinados infantiles, y; analizar el impacto en la sociedad de la cosificación de la niña/mujer y la violación de sus derechos en función de dos casos tipos: las palillonas de los desfiles patrios y los reinados infantiles.

\subsection{La cosificación de la Niña/mujer}

La sociedad hondureña se ve inmersa en una serie de estereotipos atribuidos a la mujer, dentro de los cuales se ha establecido que la misma alcanza el éxito en función de sus atributos físicos más que de sus capacidades intelectuales. Dichos estereotipos se han interiorizado de forma tal que las mujeres los consideran como una verdad absoluta y que, por ende, deben aceptarlos y verlos como algo natural. 
Al hablar de estereotipos nos referimos según la definición de Torres y Jiménez (2005) al conjunto de rasgos típicos que se suponen inherentes a los miembros de un grupo, que se transmiten a través de la repetición de normas de comportamientos y formas de entender las situaciones que nos rodean, considerando estas actitudes las óptimas en la sociedad, con el fin de ajustarse a los intereses y necesidades de los grupos dominantes.

Es importante, en este punto, conceptualizar también lo que son los estereotipos de género, que según el Alto Comisionado de las Naciones Unidas de los Derechos Humanos (ACNUDH) se define como "una opinión o un prejuicio generalizado acerca de atributos o características que hombres y mujeres poseen o deberían poseer o de las funciones sociales que ambos desempeñan o deberían desempeñar" (ACNUDH, 2017). El estereotipo referido, ha contribuido a que la cosificación y discriminación de la mujer no sea sancionada socialmente, sino más bien percibida como algo natural e inclusive aplaudida y apoyada por las mismas mujeres. Según el glosario de los talleres por la igualdad, cosificar a la mujer significa hacer uso de ella o de su imagen para finalidades que no la dignifiquen ni como mujer ni como ser humano. La forma más frecuente de cosificación de la mujer es la cosificación sexual: se la convierte en un objeto sexual a disposición del hombre (Talleres por la Igualdad, 2017).

Como consecuencia de la cosificación de la mujer surge la discriminación contra está, que para la Convención sobre la eliminación de todas las formas de discriminación contra la mujer en el artículo 1 denota toda distinción, exclusión o restricción basada en el sexo que tenga por objeto o por resultado menoscabar o anular el reconocimiento, goce o ejercicio por la mujer, independientemente de su estado civil, sobre la base de la igualdad del hombre y la mujer, de los derechos humanos y las libertades fundamentales en las esferas política, económica, social, cultural y civil o en cualquier otra esfera (ONU, 2010).

\section{Metodología}

Para abordar el análisis de los dos casos tipo (desfiles y concursos de reinas) consideramos pertinente hacer uso de la perspectiva de género que según la definición de Camargo (1999), establece una teoría social que trata de explicar las características, relaciones y comportamientos sociales de hombres y mujeres en sociedad, su origen y su evolución, destacando la existencia real del género femenino y masculino, sin dominio de uno sobre el otro, sin jerarquías y sin desigualdades.

Desde esta perspectiva, debemos considerar que lo expuesto anteriormente está íntimamente relacionado con la influencia de los roles y estereotipos tradicionales atribuidos a las mujeres en nuestra sociedad, en los cuales la apariencia física (de acuerdo a los estereotipos de la belleza occidental) es considerada fundamental para alcanzar el éxito, es decir, una apariencia enmarcada en estereotipos que no consideran un proceso de formación integral y de inclusión social.

Se analizó información de los medios de comunicación que cada año cubren en nuestro país la celebración de las fiestas patrias, en las cuales los centros educativos de nivel básico y medio participan de forma entusiasta con diversas representaciones artísticas, entre las cuales sobresalen los cuadros de palillonas. 
Se incluyó lo reportes de los diarios nacionales, blogs, transmisiones en vivo y redes sociales en septiembre 2017, identificados por titulares alusivos a las jóvenes. Aunque se celebra el fervor patrio, en los medios predominó la exaltación de los atributos físicos de las jóvenes, lo cual fue estudiado. De dichos títulos y desarrollo de sus contenidos se desprendieron una serie de frases y comentarios sobre las niñas y adolescentes (la mayoría de éstas son menores de 18 años), específicamente de las palillonas que participan en estos desfiles. Se caracterizó la cosificación de ellas a partir de dichas frases.

\section{Resultados}

Haciendo un análisis del contenido de los diarios nacionales, blogs, transmisiones en vivo, entre otros obtuvimos parámetros sobre la cosificación o no de las niñas y adolescentes (ver Tabla 1). Se encontró que se mal entiende el civismo y que lejos de exaltar los valores y enaltecer a la patria recordando a sus ilustres personajes, la atención se centró en la figura femenina, que a ritmo de canciones que no forman parte de nuestro folklor presentaron sus espectáculos para una competencia por obtener el título del mejor cuadro de palillonas o la palillona más bella de los desfiles patrios.

Se encontraron frases como "bien buenas y guapísimas”, "más ricas y sexis”, "coquetos movimientos”, "sin aliento”, “cuerpos torneados”, “diosas de la belleza”, "sexis y hermosas”, "preciosas chicas”, "guapas jovencitas”. Todas esas frases denotan la cosificación sexual de las niñas/mujeres, con la consecuente discriminación como un primer paso a la violencia contra la mujer, la cual según la convención de Belém do Pará en el capítulo 1, artículo 1 se define como "cualquier acción o conducta basada en su género, que cause muerte, daño o sufrimiento físico, sexual o psicológico a la mujer, tanto en el ámbito público como en el privado" (Convención Belém do Pará, 1996).

Tabla 1: Análisis de contenido: Palillonas

\begin{tabular}{|c|c|c|c|}
\hline $\begin{array}{l}\text { TIPO } \\
\text { DE } \\
\text { MEDI } \\
\text { O }\end{array}$ & $\begin{array}{l}\text { NOMBRE } \\
\text { DEL } \\
\text { MEDIO }\end{array}$ & TITULAR & CONTENIDO \\
\hline Blog & $\begin{array}{l}\text { Que } \\
\text { Rebane } \\
\text { Catracho }\end{array}$ & $\begin{array}{l}\text { "15 palillonas que te } \\
\text { harán suspirar” }\end{array}$ & $\begin{array}{l}\text { “Ahí no vale bandas de guerra, ahí no valen } \\
\text { cuadros de honor ahí no vale nada más que } \\
\text { verles las piernas a las hermosas palillonas. Y } \\
\text { es que es de costumbre que las que van a salir } \\
\text { de palillonas tienen que estar bien buenas o } \\
\text { ser guapísimas. Pero ojo va ojo chiky que esto } \\
\text { no es todo Honduras, no señores, lo de las } \\
\text { palillonas más ricas y sexys solo se da en } \\
\text { Tegucigalpa.” }\end{array}$ \\
\hline Diario & El Heraldo & $\begin{array}{l}\text { “Vota: ¿Quién es la } \\
\text { palillona más bella de } \\
\text { Honduras este 2016?” }\end{array}$ & $\begin{array}{l}\text { "Las palillonas ocupan siempre un lugar } \\
\text { especial en la celebración de la emancipación } \\
\text { política de Honduras y este } 195 \text { aniversario } \\
\text { deslumbraron con un singular brillo y } \\
\text { coquetos movimientos.” }\end{array}$ \\
\hline
\end{tabular}




\begin{tabular}{|c|c|c|c|}
\hline Diario & La Prensa & $\begin{array}{l}\text { "Las palillonas que se } \\
\text { robaron el show en } \\
\text { los desfiles" }\end{array}$ & $\begin{array}{l}\text { "Sonrisas, besos y bailes sensuales regalaron } \\
\text { ayer las bellas palillonas al público durante la } \\
\text { celebración del } 194 \text { aniversario de } \\
\text { independencia de Honduras, Como ya es } \\
\text { costumbre, uno de los principales atractivos de } \\
\text { los desfiles del } 15 \text { de septiembre son las lindas } \\
\text { palillonas y bastoneras que con sus coloridos y } \\
\text { cortos vestidos dejaron sin alientos a muchos." }\end{array}$ \\
\hline Diario & La Tribuna & $\begin{array}{l}\text { "Las mejores } \\
\text { fotografías de } \\
\text { palillonas en } \\
\text { Tegucigalpa” }\end{array}$ & $\begin{array}{l}\text { "Rostros, cuerpos torneados y rítmicos } \\
\text { movimientos convierten a las palillonas } \\
\text { hondureñas en unas diosas de la belleza." }\end{array}$ \\
\hline $\mathrm{TV}$ & Canal 6 & $\begin{array}{l}\text { "Palillonas } \\
\text { engalanaron los } \\
\text { desfiles en Honduras" }\end{array}$ & $\begin{array}{l}\text { "Preciosas chicas de los distintos colegios } \\
\text { engalanaron los desfiles por los } 195 \\
\text { aniversario de la independencia." }\end{array}$ \\
\hline TV & $\mathrm{HCH}$ & $\begin{array}{l}\text { "Las palillonas del } \\
\text { instituto central } \\
\text { arrancan suspiros en } \\
\text { el \#196aniversario } \\
\text { \#fiestaspatrias2017” }\end{array}$ & $\begin{array}{l}\text { "Sin embargo, quienes acapararon las miradas } \\
\text { y el suspiro de muchos, fueron las sexys y } \\
\text { hermosas palillonas del Central, quienes } \\
\text { moviendo sus caderas despertaron la } \\
\text { imaginación de algunos que no pudieron } \\
\text { ocultar su intención de fotografiarse con las } \\
\text { fascinantes chicas.” }\end{array}$ \\
\hline Radio & $\begin{array}{l}\text { Radio } \\
\text { América }\end{array}$ & $\begin{array}{l}\text { “La bella palillona } \\
\text { de Danlí que impacta } \\
\text { a Honduras” }\end{array}$ & $\begin{array}{l}\text { “Guapas jovencitas engalanaron los desfiles } \\
\text { patrios del } 15 \text { de Septiembre y como es } \\
\text { costumbre, muchas este sábado destacaron en } \\
\text { la portada de los distintos diarios } \\
\text { hondureños.” }\end{array}$ \\
\hline
\end{tabular}

Fuente: El Heraldo, La Prensa, La Tribuna, Canal 6, HCH, Radio América

Con relación a los reinados infantiles de belleza, los medios de comunicación no son tan abiertos en cuanto al lenguaje utilizado sobre ellos. Sin embargo, las imágenes que presentan evidencian cómo las niñas son objeto de sexualización a partir de la vestimenta, maquillaje y poses que son obligadas a asumir, tal como podemos observar en la Tabla 2. 
C. López, et al. / 1nnovare Vol. 7, Núm. 1 (2018)

Tabla 2: Análisis de contenido: Reinados infantiles

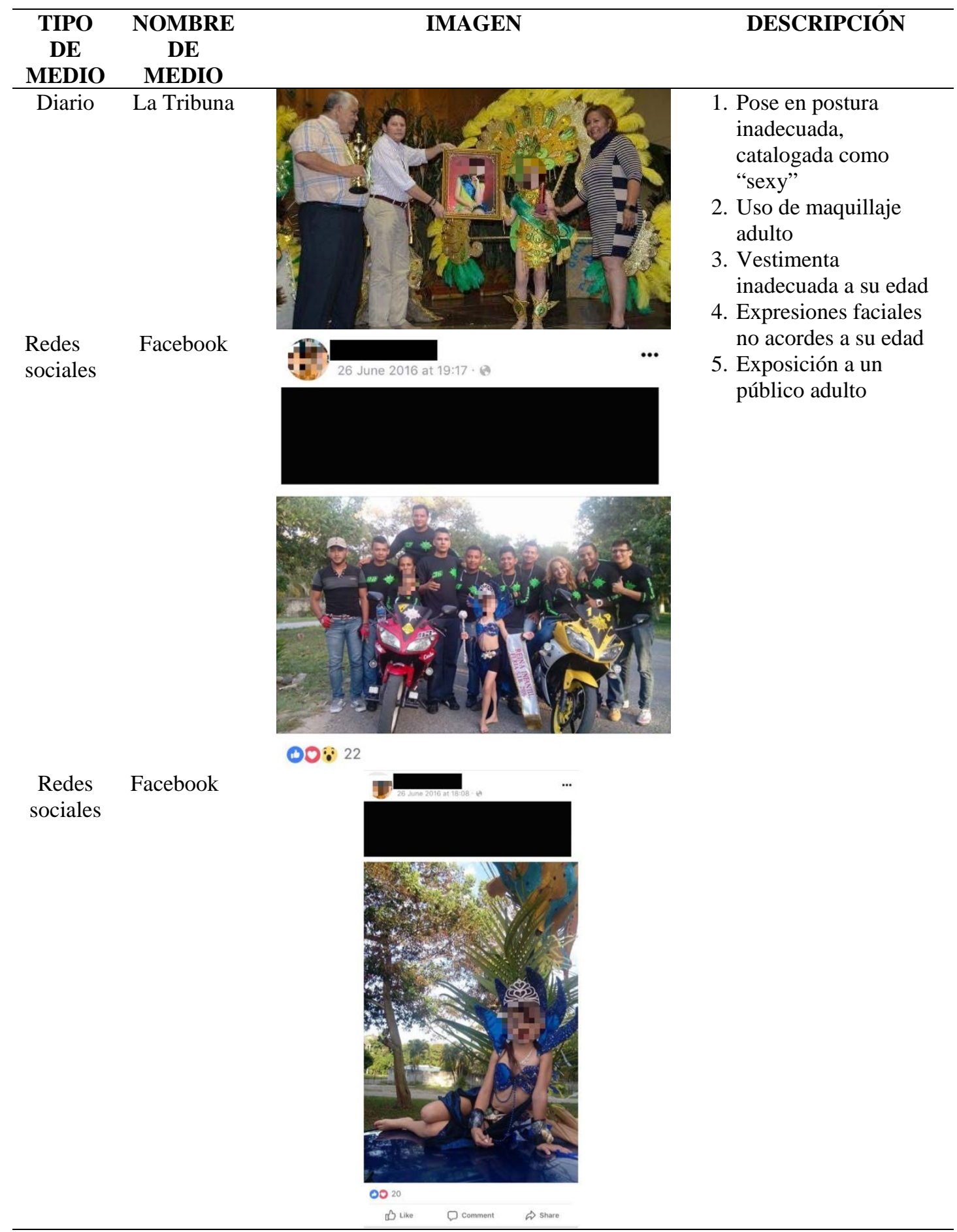

Fuente: Diario La Tribuna, Facebook 


\section{Discusión}

La finalidad del desfile o el concurso de reinas es ser seleccionadas entre las favoritas del público, que se vuelve cómplice consciente o inconscientemente de la explotación de la imagen de la niña, así como de sus derechos. Cómplices son también los organizadores de dichos eventos que en ningún momento consideran que se están violentando sus derechos fundamentales e inclusive realizan una categorización a lo interno de los concursos que afecta su desarrollo psicológico y moral al encasillarse en estereotipos que son afianzados desde estos concursos. Debemos tener presente que los medios de comunicación juegan un papel fundamental dentro de la sociedad ya que se han convertido en un agente de socialización transmisor de patrones y estilos, asumiendo también un rol educativo e inclusive se les ha denominado, en el caso de la televisión, como niñeras virtuales.

Considerando el caso de los certámenes infantiles de belleza, podemos establecer que los mismos contribuyen a la sexualización que según el Parlamento Europeo (2012) se define como "imposición de una sexualidad adulta a los niños y niñas que no se encuentran ni emocional, ni psicológica, ni físicamente preparadas para ella en la fase de desarrollo en la que se encuentran." Por su parte, en su investigación bibliográfica, Bell (2012) plantea que "De este modo, su calidad como persona es valorada en función de su atractivo físico y sexual por sobre sus capacidades y aptitudes".

La sexualización que se lleva a cabo a partir de estos dos casos tipo contribuye significativamente a que se desarrolle una hipersexualización de las niñas que según el Informe Bailey (2011) se define como "La sexualización de las expresiones, posturas o códigos de la vestimenta considerados como demasiado precoces”. Tanto las palillonas de los desfiles patrios como las niñas en los reinados infantiles se convierten en blanco de las críticas, comentarios y cosificación sexual a manos de una sociedad cómplice que toma estos actos como algo natural sin ver más allá de las repercusiones que pueden tener, tanto en el ámbito social como psicológico que conllevan a una madurez precoz, distorsión de su realidad y pérdida de vivencias propias de su edad; violentando de esta forma los derechos fundamentales de la niña/mujer.

\subsection{Niña/mujer y derechos}

Partiendo de lo anterior, es necesario abordar el papel que el Estado juega en los casos tipo planteados y las obligaciones tanto convencionales como nacionales derivadas del marco jurídico, tanto de protección de la niñez como de la mujer que son grupos en situación de vulnerabilidad, iniciando con la jerarquía normativa aplicable al sistema jurídico hondureño.

La Convención de Derechos del niño, en su Preámbulo en el párrafo 10 establece que, como se indica en la Declaración de los Derechos del Niño, "el niño, por su falta de madurez física y mental, necesita protección y cuidado especiales, incluso la debida protección legal, tanto antes como después del nacimiento" (UNICEF, 1989).

Por su parte, Mejía (2012), argumenta que la obligación de respetar tiene un carácter negativo en cuanto comprende, fundamentalmente, el deber del Estado de abstenerse de interferir en los ejercicios de los mismos, ya que "el ejercicio de la función pública tiene unos límites que 
derivan de que los derechos humanos son atributos inherentes a la dignidad humana y, consecuencia, superiores al poder del Estado.” Por su parte, la obligación de garantizar tiene un carácter positivo, ya que el Estado de Honduras tiene el deber de adoptar tales medidas que sean necesarias para asegurar el ejercicio de tales derechos, y esto implica "organizar todo el aparato gubernamental y, en general todas las estructuras a través de las cuales se manifieste el ejercicio del poder público, de manera tal que sean capaces de asegurar jurídicamente el libre y pleno ejercicio de los derechos humanos”.

Aunado a lo anterior, la citada Convención determina en su Parte 1, Artículo 1 que "se entiende por niño todo ser humano menor de dieciocho años de edad, salvo que, en virtud de la ley que le sea aplicable, haya alcanzado antes la mayoría de edad” (UNICEF, 1989).

Como se ha dicho en la cúspide de la jerarquía normativa, en los casos estudiados, contamos con la Convención de Derechos del Niño, que determina que un niño es una persona humana; en la Constitución de la República de Honduras prescribe en el artículo 59 que "La persona humana es el fin supremo de la sociedad y del Estado. Por ende, el Estado al estar en la obligación de proteger y respetar a la persona humana, adquiere también la obligación de proteger a la infancia, lo cual está plasmado también en el artículo 119 que dice "El Estado tiene la obligación de proteger a la infancia”. Los niños gozarán de la protección prevista en los acuerdos internacionales que velan por sus derechos. Las leyes de protección a la infancia son de orden público y los establecimientos oficiales destinados a dicho fin tiene carácter de centros de asistencia social (Constitución de la República, 1982).

Al ser grupos en condición de vulnerabilidad, el Estado adquiere una mayor obligación en la protección de los derechos del infante y las mujeres, entre otros. Sin embargo, el Estado ha hecho caso omiso a las obligaciones adquiridas a partir de las ratificaciones de las convenciones supra que significa por encima de la Constitución y las leyes indicadas anteriormente, así como a los artículos plasmados en la misma Constitución.

En primer lugar, como se ha dicho, al no realizar las acciones encaminadas a garantizar los derechos antes referidos y al no respetar desde las instituciones públicas dichos derechos, el Estado se vuelve responsable por omisión y por acción de la institucionalización de la cosificación sexual de las niñas, y como consecuencia al ser promovido por el mismo Estado, se ha naturalizado la reproducción de noticias y lenguaje que afecta el desarrollo moral y psicológico de las niñas.

Con relación a este último punto, en el Código de la Niñez, Capítulo 4, sección segunda en el artículo 34 se establece que "Los medios de comunicación social están obligados a respetar la vida personal de los niños. No podrán, en consecuencia, publicar entrevistas, informes, noticias o datos que se relacionen con aquella o con la de su familia o la de sus relaciones, si de cualquier modo pueden afectar su honra. La contravención de esta norma se sancionará en la forma prevista en el artículo 32, anterior (Código de la niñez, 1996).

La Real Academia Española de la Lengua define honra como "estima y respeto de la dignidad propia”. Partiendo del articulado anterior, de la definición de honra y de la conducta mostrada por los medios de comunicación que deshonran la dignidad de las niñas al referirse a ellas como objetos de placer sexual, es evidente que se ha violentado por parte de los medios la anterior disposición. 
Pese a ello, el Estado no ha sancionado estas conductas de los medios y esto queda evidenciado al observar en las diferentes portadas de diarios, blogs de internet, redes sociales y transmisiones en vivo que se violentan en su totalidad tanto el artículo anteriormente mencionado como las convenciones y el Código de la Niñez en que se establece en el artículo 32 lo siguiente “...Quien autorice, facilite o permita la publicación, reproducción, exposición, venta, distribución o utilización de cualquier información que violente lo dispuesto por esta norma será sancionado con una multa de cinco mil (L. 5,000.00) a cincuenta mil (L. 50,000.00) lempiras, atendida la gravedad de la infracción (Código de la Niñez, 1996).

Continuando con el papel de los medios de comunicación, en relación a ellos, la convención Belém do Pará, establece en el artículo 6 del capítulo 1, en el inciso b “el derecho de la mujer a ser valorada y educada libre de patrones estereotipados de comportamientos y prácticas sociales y culturales basadas en conceptos de inferioridad o subordinación” (Convención Belém do Pará, 1996). De igual forma en el Artículo 8 se lee que Los Estados Parte convienen en adoptar, en forma progresiva, medidas específicas, inclusive programas para: “Alentar a los medios de comunicación a elaborar directrices adecuadas de difusión que contribuyan a erradicar la violencia contra la mujer en todas sus formas y a realizar el respeto a la dignidad de la mujer”.

El manejo por parte de los medios de comunicación de la imagen de las palillonas de los desfiles patrios conlleva el afianzamiento de los estereotipos relacionados con la belleza. El establecer un top 10 de las más bellas o votaciones por quién es la palillona más agraciada no hace más que reforzar la creencia de que el éxito se alcanza por medio de la belleza física. Algunas palillonas se han vuelto famosas al ser sometidas a votaciones en redes sociales y algunas pasaron a ser figuras públicas y se han dedicado a manejar páginas en redes sociales que a su vez les han llevado a ser populares y parte de la farándula nacional, incursionando en los medios de comunicación como presentadoras. A la edad que fueron votadas como las mejores palillonas eran adolescentes y menores de edad, por lo que sus derechos fueron violentados bajo el visto bueno de la sociedad que fue permisiva al apoyar las votaciones públicas en las redes sociales y otros medios.

Como establecimos con anterioridad, los medios de comunicación juegan un papel muy importante dentro de la sociedad y son considerados como un agente socializador, esto significa que forman parte de los agentes socializadores que influyen en la formación del individuo desde el momento mismo de su nacimiento. En ese sentido, la carga de estereotipos transmitidos por dichos medios se interioriza al grado de considerar como algo natural el hecho de que la mujer sea vista como un objeto sexual o como una cosa que existe para deleite del género masculino. Dicha interiorización actúa de forma negativa en la niña/mujer pues hace que esta asuma que solamente puede alcanzar el éxito si reúne las cualidades establecidas en dichos estereotipos.

El problema radica en el elevado nivel de sexualización que se está transmitiendo a través de los medios, del cual no existe el control adecuado por parte de las autoridades ni de los padres de familia. Otra definición de sexualización dada por Papadopoulos (2010) la considera como la "imposición de la sexualidad adulta en niños y jóvenes antes que sean capaces de lidiar con esto, mental, emocional o físicamente”. La autora plantea que el hecho de que se vea como algo natural la imagen sexualizada de la niña/mujer se debe a una serie de contenidos mediáticos 
cargados de imágenes sexuales, así como el aumento de canales exclusivos que se enfocan en ese aspecto en particular.

En el año 2007 la Asociación de la Psicología Americana (APA), presentó un informe sobre la sexualización de las niñas. En este se identificaron cuatro componentes de la sexualización que difieren, como se planteó anteriormente, del desarrollo sexual saludable. Según APA (2007), se dice que existe sexualización cuando:

1. La valoración de una persona viene únicamente dada por su apariencia o comportamiento sexual excluyendo otras características.

2. Una persona adjudicada dentro de un parámetro en el que el atractivo físico (estrictamente definido) se equipara con ser sexy.

3. Una persona es objetivada sexualmente, esto es, convertida en una cosa para el uso sexual de otros, en vez de ser vista como una persona con la capacidad de actuar independientemente y tomar sus propias decisiones.

4. La sexualidad es inapropiadamente impuesta a una persona.

Considerando lo anteriormente expuesto, el punto 1 y 2 están presentes en los casos tipo que estamos abordando, ya que tanto las palillonas de los desfiles patrios como las niñas que participan en los reinados infantiles compiten por ganarse un título enmarcado en la noción que los medios de comunicación y la sociedad misma han establecido sobre la belleza, sin estar conscientes que sus derechos se están violentando, lo que se afianza por el desconocimiento de los mismos tanto de parte de ellas como de los adultos responsables de ellas, entiéndase padres de familia, tutores o familiares.

El problema de que la cosificación de la niña/mujer sea algo tan cotidiano conlleva según Bell (2012) a que exista también el riesgo de que las niñas se auto-sexualicen y comiencen a pensar en sí mismas como objeto. Esta auto-objetivación se presenta como un proceso en el cual las niñas piensan y se tratan a sí mismas y sus cuerpos como objeto de los deseos de otros, es decir, internalizan la perspectiva del observador en su yo físico y se tratan a ellas mismas como objeto que son observados y evaluados en función de su apariencia.

Todo lo antes mencionado y que ocurre desde el mismo Estado por acción, al promover desde sus instituciones educativas este tipo de eventos, y por omisión cuando no sanciona a los medios de comunicación por las conductas expuestas, es el resultado de la no aplicación de las principales convenciones de derechos de la mujer que hemos venido analizando y que Honduras ha ratificado, las cuales procedemos a subrayar en puntos torales como sigue.

La Convención sobre la Eliminación de todas las formas de Discriminación contra la Mujer, por sus siglas en inglés CEDAW, señala en su Preámbulo párrafo séptimo "Recordando que la discriminación contra la mujer viola los principios de la igualdad de derechos y del respeto de la dignidad humana, que dificulta la participación de la mujer, en las mismas condiciones que el hombre, en la vida política, social, económica y cultural de su país, que constituye un obstáculo para el aumento del bienestar de la sociedad y de la familia y que entorpece el pleno desarrollo de las posibilidades de la mujer para prestar servicio a su país y a la humanidad" (CEDAW, 1998). Y continúa en el antepenúltimo párrafo del preámbulo de la citada convención, "Reconociendo que para lograr la plena igualdad entre el hombre y la mujer es 
necesario modificar el papel tradicional tanto del hombre como de la mujer en la sociedad y en la familia” (CEDAW, 1998).

En este punto, es importante hacer hincapié sobre la obligación de los estados de modificar el papel tradicional tanto del hombre como de la mujer en la sociedad, hecho que subraya el artículo 5 que dice Los Estados Parte tomarán todas las medidas apropiadas para: a) Modificar los patrones socioculturales de conducta de hombres y mujeres, con miras a alcanzar la eliminación de los prejuicios y las prácticas consuetudinarias y de cualquier otra índole que estén basados en la idea de la inferioridad o superioridad de cualquiera de los sexos o en funciones estereotipadas de hombres y mujeres (CEDAW, 1998).

Por lo tanto, partiendo de los casos tipo; el Estado ha omitido su obligación convencional de modificar los patrones socioculturales entre hombres y mujeres, en los cuales se ha secundarizado el papel de las niñas a objetos de placer visual y sexual que en nada abona a la eliminación de estos estereotipos. La mujer en su lucha por los derechos ha pasado por etapas como: el derecho al voto, a la anticoncepción, derechos civiles y una serie de derechos que le han permitido salir al espacio público.

Sin embargo, cuando en estos escenarios la mujer sale al espacio público en eventos de belleza, el estereotipo de inferioridad de la mujer persiste, pues su papel "protagónico" como se ha dicho, es en beneficio del hombre que asume el papel de consumidor "de producto", y toma fuerza el discurso de que el espacio público pertenece de facto al hombre, porque cuando la mujer lo asume es para ser objetivada, sexualizada y como consecuencia discriminada. Nada más alejado de la obligación Estatal de eliminar los estereotipos que han sometido a la mujer y que le discriminan como sujetas de derechos que aspiran a asumir papeles en pie de igualdad con el hombre, especialmente en los ámbitos de toma de decisiones.

Más grave aún, es que según la CEDAW (1998), en su artículo 10, el Estado debe adoptar todas la medidas apropiadas para que desde la educación se elimine la discriminación contra la mujer, y específicamente aplicado a los casos tipo, señala el inciso C, "que se debe eliminar todo concepto estereotipado de los papeles masculino y femenino en todos los niveles y formas de enseñanza...mediante la modificación de los libros y programas escolares...”, es decir que el Estado estaría obligado a modificar o en todo caso eliminar estos "programas escolares", que son actividades que hasta se califican con puntuación a favor de las participantes, porque como se reitera, estereotipan a las niñas en un rol de producto de consumo o cosificación sexual.

Esta omisión de modificar los roles tradicionales de la mujer, en este caso de las niñas, trae como consecuencia la violencia contra la mujer por el hecho de serlo. Esta violencia va desde la violencia física, sexual y psicológica a la que se ve sometida porque social y culturalmente se ha aceptado su inferioridad con el hombre, cuando se le expone como accesorio de consumo, pasando de ser sujetas de derechos a meros objetos de placer. Es claro que la cosificación y sexualización de las niñas causa daño psicológico en ellas, al internalizar la perspectiva de ellas mismas como un objeto.

El Artículo 4 de la Convención Belém do Pará señala que toda mujer tiene derecho al reconocimiento, goce, ejercicio y protección de todos los derechos humanos y a las libertades consagradas por los instrumentos regionales e internacionales sobre derechos humanos. Estos derechos comprenden, entre otros: el derecho a que se respete su integridad física, psíquica y 
moral (Convención Belém do Pará, 1996). De este artículo y en los casos analizados, se ven violentados, entre otros, el derecho a que se respete la integridad de las niñas por las razones ya expuestas.

Y es que, esa correlación entre la cosificación sexual que trae como consecuencia discriminación y violencia hacia la mujer, tiene asidero legal y convencional cuando el artículo 6 de la Convención citada anteriormente, es categórica al decir que el derecho de toda mujer a una vida libre de violencia incluye, entre otros: a. el derecho de la mujer a ser libre de toda forma de discriminación, y b. el derecho de la mujer a ser valorada y educada libre de patrones estereotipados de comportamiento y prácticas sociales y culturales basadas en conceptos de inferioridad o subordinación (Convención Belém do Pará, 1996). Por lo que es claro que es desde el mismo Estado que se discrimina y se produce lo que podríamos llamar violencia institucional contra las niñas.

En cuanto a la obligación estatal de prevenir, sancionar y eliminar la violencia, la referida Convención establece en el artículo 7 que Los Estados Parte condenan todas las formas de violencia contra la mujer y convienen en adoptar, por todos los medios apropiados y sin dilaciones, políticas orientadas a prevenir, sancionar y erradicar dicha violencia y en llevar a cabo lo siguiente: a. abstenerse de cualquier acción o práctica de violencia contra la mujer y velar por que las autoridades, sus funcionarios, personal y agentes e instituciones se comporten de conformidad con esta obligación; b. actuar con la debida diligencia para prevenir, investigar y sancionar la violencia contra la mujer; c. incluir en su legislación interna normas penales, civiles y administrativas, así como las de otra naturaleza que sean necesarias para prevenir, sancionar y erradicar la violencia contra la mujer y adoptar las medidas administrativas apropiadas que sean del caso;... h. adoptar las disposiciones legislativas o de otra índole que sean necesarias para hacer efectiva esta Convención (Convención Belem do Pará, 1996).

Es decir que, en base a lo anterior, la violencia contra la mujer no solo debe ser condenada por el Estado, éste está obligado a velar que las autoridades en las instituciones educativas públicas y privadas, así como las autoridades municipales, departamentales y cualesquier otra involucrada en la organización de este tipo de eventos se comporten de conformidad con esa obligación, y en ese sentido, tal como señala el artículo 12 de la citada convención, cuando existe la violación del artículo 7 se puede acudir a la instancia interamericana a denunciar al Estado, ello en relación con la jurisprudencia de la Corte Interamericana de Derechos Humanos.

En el caso González y otras, la Corte Interamericana ha dicho que si bien "no toda violación de un derecho humano de una mujer implica necesariamente una violación de las disposiciones de la Convención de Belém do Pará, cuando se produce la violación del citado artículo 7, la violencia contra la mujer es un tema de derechos humanos, puesto que es perpetrada por el mismo Estado, que desde la visión clásica de los derechos humanos, según Nikken (1994), la noción de derechos humanos se corresponde con la afirmación de la dignidad de la persona frente al Estado.

El poder público debe ejercerse al servicio del ser humano: no puede ser empleado lícitamente para ofender atributos inherentes a la persona y debe ser vehículo para que ella pueda vivir en sociedad en condiciones cónsonas con la misma dignidad que le es consustancial, por lo que se reitera que, al abstenerse el Estado de cumplir sus obligaciones convencionales, es el autor 
de la violación de los derechos humanos de las niñas por no prevenir, sancionar ni erradicar la violencia contra estas y más bien fomentar y ejecutar desde la institucionalidad la cosificación sexual de las niñas y su consecuente discriminación y violencia contra éstas.

Para finalizar, el Artículo 8 de la referida Convención establece que Los Estados Parte "convienen en adoptar, en forma progresiva, medidas específicas, inclusive programas para: a. fomentar el conocimiento y la observancia del derecho de la mujer a una vida libre de violencia, y el derecho de la mujer a que se respeten y protejan sus derechos humanos; b. modificar los patrones socioculturales de conducta de hombres y mujeres, incluyendo el diseño de programas de educación formales y no formales apropiados a todo nivel del proceso educativo, para contrarrestar prejuicios y costumbres y todo otro tipo de prácticas que se basen en la premisa de la inferioridad o superioridad de cualquiera de los géneros o en los papeles estereotipados para el hombre y la mujer que legitiman o exacerban la violencia contra la mujer;...” (Convención Belém do pará, 1996).

Es claro que las anteriores, son obligaciones que conminan a los Estados a adoptar políticas públicas y de educación con perspectiva de género, dictaminar medidas positivas que tengan por objeto eliminar la discriminación y violencia como consecuencia de los estereotipos de género tradicionales, con el objeto de garantizar los derechos humanos de las mujeres y las niñas, puesto que al no hacerlo y tal como ha quedado establecido en la jurisprudencia que la Corte Interamericana de Derechos Humanos ha dictado al efecto, en el citado caso Campos Algodoneros vs México al decir que "la creación y uso de estereotipos se convierte en una de las causas y consecuencias de la violencia de género en contra de la mujer” (Gómez, 2009).

\subsection{Impacto social de la cosificación de la niña/mujer}

El hecho de que la cosificación de la niña/mujer sea imperceptible por el grueso de la sociedad hondureña tiene un impacto negativo, pues se vuelve algo cotidiano que se interioriza al grado de que los mismos responsables del cuidado y educación de la niña/mujer, sean padres de familia, tutores, familiares o el Estado mismo se vuelvan cómplices de dicho proceso. Por ello, es "normal” por ejemplo, observar como en las redes sociales los padres de familia, orgullosos de sus "princesas" publican fotografías en las cuales se les pide posar de manera sexy o picaresca, con atuendos nada acorde a su edad pues la ropa de niña ya no existe y ha sido sustituida por modas que son versiones en miniatura de la vestimenta apta para mujeres mayores de 18 años.

Que los padres de familia accedan a que sus hijas participen en certámenes de belleza infantil o como palillonas de los desfiles patrios nos demuestra la carencia de conocimiento adecuado de las repercusiones que ello puede tener. Observamos inclusive que motivan a sus familiares y amistades a votar por ellas en la elección en los reinados de belleza o en las redes sociales, generando un espíritu de competitividad que hace perder la perspectiva de lo que sucede realmente y de lo que estas acciones conllevan para sus hijas en particular y las niñas en general.

Por todos es sabido que la información y fotografías publicadas en redes sociales se vuelve de dominio público y están al alcance de cualquiera que tenga acceso a las redes sociales, blogs, periódicos y otros medios electrónicos, lo que incluye a personas que se dedican a actividades ilícitas como pedófilos, tratantes de personas e inclusive a los que trabajan en el mundo de la 
pornografía infantil. Las niñas se vuelven entonces presa fácil de quien tenga acceso a sus imágenes, pues se puede hacer uso de ellas sin que se tenga el permiso correspondiente. El no dimensionar las repercusiones de las acciones que se realizan conlleva al incremento de la sexualización de las niñas.

Generalmente los concursos de reinados infantiles incluyen en su programa una muestra de talentos y en estos el más común es el baile. También en esta práctica las niñas son llevadas al plano adulto al montar con ellas coreografías con música inapropiada a su edad, como el famoso "perreo" que es aplaudido con sonrisas sin reparar en el mensaje transmitido por la letra de este género musical.

Los cánones de belleza se han ido transformando y las niñas han ido perdiendo la oportunidad de vivir una infancia saludable, acorde a su grado de madurez y en lugar de jugar a la rayuela, saltar la cuerda o correr y ensuciarse, juegan con muñecas que transmiten esos cánones, con cuerpos estilizados, rostros maquillados y vestuario inapropiado.

De igual forma, el afianzamiento de los estereotipos establecidos con relación al concepto de la belleza en las sociedades occidentalizadas, incluyendo la nuestra, ha llevado al surgimiento de nuevas problemáticas relacionadas con el ámbito de la salud física y emocional. Estos estándares de belleza imponen un molde en el cual, como lo hemos expresado anteriormente, el éxito solo es viable asociado a la apariencia física. Un cuerpo esbelto, con medidas perfectas impuesto por una sociedad de consumo es lo que garantiza que una mujer pueda sobresalir en nuestra sociedad. Ante tal presión, los casos de anorexia y bulimia se vuelven más comunes y desembocan en una baja autoestima que, a la larga, lleva a la aceptación de la cosificación de la mujer como objeto sexual.

Si bien, no existen estadísticas claras con relación a los casos de anorexia y bulimia en Honduras, como lo establece en su tesis doctoral María José Aguirre (2013) El grupo con más riesgo abarca las edades de 14 a 18 años. Hay también estudios que amplían esta edad desde los 12 hasta los 25 años de edad. En los últimos años cada vez más jóvenes están enfrentando este trastorno. Las estadísticas de la anorexia en el mundo son bastante alarmantes. Se calcula que afecta entre el $0.5 \%$ al 3\% de la población mundial de adolescentes, convirtiéndola en la tercera enfermedad crónica más común dentro de ese grupo. De todos los casos de anorexia, un $90 \%$ afecta a mujeres mientras que sólo el $10 \%$ a los hombres.

Los medios de comunicación se han convertido en el mayor instigador de la cosificación de la mujer al promover programas inadecuados y tolerar en su programación la exposición de contenidos que afianzan la imagen estereotipada de la mujer, explotada en la publicidad, en la programación diaria y en los mensajes subliminales. Considerando lo anterior, nos encontramos con una sociedad cada vez más permisiva a la cosificación de la mujer, pese a las conquistas sociales logradas por esta y a las voces que se alzan para condenar esta situación. Este proceso de cosificación ha conllevado a un incremento de la violencia hacia esta, que puede evidenciarse de dos formas; una de ellas es a partir de comportamientos "sutiles" que no llevan implícito el uso de la violencia física, pero sí el de la violencia verbal, que lamentablemente es permitida e inclusive aceptada por la misma mujer que ha interiorizado los estereotipos establecidos.

Cuando hablamos de comportamientos "sutiles" hacemos referencia a los comentarios acerca del cuerpo de la mujer como los tradicionales piropos que tienen implícito un lenguaje sexual 
y que han quedado de manifiesto en el análisis de contenido presentado en este trabajo, relacionado con el caso tipo de las palillonas de los desfiles patrios. Esta práctica se ha vuelto común en nuestra sociedad y hasta se considera parte de nuestra cultura, por lo que la misma no es lo suficientemente sancionada, más que por aquellas mujeres que han logrado entender las connotaciones que dicho lenguaje tiene. En la práctica, se tolera el uso de dichas frases y muchas las reciben como "halagos" sin tener consciencia de que las mismas denigran y vulneran la imagen de la mujer. La otra es cuando hablamos de comportamientos "hostiles", aquellos que llevan implícitos el uso de la violencia física hacia la mujer y el que esta permita que se le minimice y agreda considerándolo algo natural e inclusive sintiéndose culpable por provocar la misma.

Según lo planteado por Telesur (2017) El Observatorio de la Violencia de la Universidad Nacional Autónoma de Honduras (UNAH) informó que al menos 187 mujeres fueron asesinadas de forma violenta durante el primer semestre de este año. La mayoría de las víctimas caen en manos de sus parejas al ser intimidadas "con golpes, violencia psicológica y sexual hasta quitarles la vida”. Según cifras de organizaciones feministas, el 70 por ciento de estas muertes se produjeron en mujeres menores de 25 años mientras el restante 30 por ciento eran mayores de los 30 años (Telesur TV, 2017). Como podemos observar, no se trata de una postura feminista sino más bien de concientizar a la sociedad sobre las implicaciones que tiene esta problemática en la misma.

\section{Conclusiones}

1. La cosificación de la niña/mujer se caracteriza por el uso de un lenguaje hostil hacia ellas, con frases cargadas de contenido sexual en el caso de las palillonas de los desfiles patrios en las cuales se resaltan sus atributos físicos dejando de lado otras cualidades inherentes al ser humano. De igual forma sucede en el caso de los reinados infantiles de belleza con el uso de la vestimenta inadecuada para sus edades, así como de maquillaje y montaje de espectáculos con música de contenido sexual que denigra su integridad.

2. El Estado y la sociedad misma ha fallado en la protección de los derechos de la niña/mujer pues como hemos podido evidenciar, se han vulnerado sus derechos más elementales al someterlas al escarnio popular a través de la explotación de su imagen tanto en el caso de las palillonas de los desfiles patrios como en el de los reinados infantiles de belleza. La niña/mujer se vuelve un objeto para el deleite del hombre, y los encargados de su protección se vuelven cómplices al no aplicar las convenciones internacionales y las leyes nacionales que reclaman su protección. Los medios de comunicación se vuelven la plataforma encargada de afianzar este proceso de cosificación jugando un papel negativo como agente socializador.

3. Las consecuencias sociales de la cosificación de la mujer son variadas e incluyen aspectos relacionados con la salud física, emocional y la seguridad personal. El interiorizar los estereotipos establecidos por la sociedad y afianzarlos ha repercutido de forma negativa en el crecimiento sano y libre de prejuicios de la niña/mujer que se ve atrapada en una sociedad que demanda una apariencia física aferrada a los cánones de belleza occidentalizados para garantizar el éxito personal y profesional. En ese sentido problemas como la anorexia, 
bulimia y violencia hacia la niña/mujer son cada vez más comunes y en definitiva vulneran sus derechos y las encasillan en esquemas que no contribuyen a su crecimiento personal.

\section{Referencias bibliográfica}

ACNUDH. (2017). Recuperado el 2 de Octubre de 2017, de http://www.ohchr.org/SP/Issues/Women/WRGS/Pages/GenderStereotypes.asp

American Psychological Association,Task Force on the Sexualization of Girls. (2007). Report of the APA Task Force on the Sexualization of Girls. Recuperado el 29 de Septiembre de 2017, de https://www.apa.org/pi/women/programs/girls/report-full.pdf

Bailey, R. (2011). Report of an Independent Review of the Commercialisation and Sexualisation of Childhood. Reino Uniddo: Crown. Recuperado el 9 de Octubre de 2017, de https://www.gov.uk/government/uploads/system/uploads/attachment_data/file/175418 /Bailey_Review.pdf

Bell, P. (2012). Sexualización de la niñez en los medios . Santiago, Chile. Recuperado el 28 de Septiembre de 2017, de https://www.cntv.cl/cntv/site/artic/20120614/asocfile/20120614103928/sexualizaci n_de_la_ni_ez_en_los_medios_el_debate_internacional.pdf

Camargo, J. (1999). Género e Investigación Social. Curso de Formación en Género. (Primera ed.). (Sibauste, Ed.) Panamá: Instituto de la Mujer de la Unuversidad de Panamá. Recuperado el 23 de Septiembre de 2017

Canal 6. (15 de Septiembre de 2015). \#Honduras: Fervor patriótico en los desfiles por el cumpleaños de la Patria. San Pedro sula, Honduras. Recuperado el 27 de Septiembre de 2017, de https://www.canal6.com.hn/noticias-de-honduras/honduras-fervorpatriotico-en-los-desfiles-por-el-cumpleanos-de-la-patria.html

CEPAL. (2017). Observatorio de igualdad de género. https://oig.cepal.org/es/autonomias/autonomia-fisica. Recuperado el 25 de septiembre de 2017.

Codigo de la Niñez. (1996). Tegucigalpa, Honduras. Recuperado el 2 de Octubre de 2017, de https://www.unicef.org/honduras/codigo_ninez_adolescencia.pdf

Constitución de la República de Honduras. (1982). Tegucigalpa, Honduras: OIM EDITORIAL S.A de C.V. Recuperado el 25 de Septiembre de 2017

Convención de Belém do Pará. (1996). Belém do Pará, Brasil. Recuperado el 26 de Septiembre de 2017, de https://www.unicef.org/argentina/spanish/ar_insumos_ConvencionBelém.pdf 
Convención sobre la eliminación de todas las formas de discriminación contra la mujer (CEDAW). (1998). Panama. Recuperado el 29 de Septiembre de 2017, de https://www.unicef.org/panama/spanish/MujeresCo_web.pdf

Gomez, F. (2009 de Noviembre de 16). Resumen de los aspecctos más importante de la sentencia de la Corte Interamericana de Derechos humanos en el Caso González y otras ("Campo algodonero") vs. Mexico. Recuperado el 9 de Octubre de 2017, de https://moodle.ufsc.br/pluginfile.php/1033701/mod_resource/content/1/ciudad\%20juar ez_resumo.pdf

Habla como Habla. (15 de Septiembre de 2017). Las palillonas del instituto central arrancan suspiros en el \#196aniversario \#FIESTASPATRIAS2017. Tegucigalpa, Honduras. Recuperado el 26 de Septiembre de 2017, de https://www.hch.tv/2017/09/15/laspalillonas-del-instituto-central-arrancan-suspiros-en-el-196aniversariofiestaspatrias2017/

Hondudiario. (15 de Septiembre de 2016). Hermosas palillonas en el 195 aniversario de independencia. San Pedro sula, Honduras. Recuperado el 26 de Septiembre de 2017, de http://hondudiario.com/2016/09/15/hermosas-palillonas-en-el-195-aniversario-deindependencia/

La Prensa. (16 de Septiembre de 2015). Las palillonas que se robaron el show en los desfiles. San Pedro Sula, Honduras. Recuperado el 25 de Septiembre de 2017, de http://www.laprensa.hn/honduras/880565-410/las-palillonas-que-se-robaron-el-showen-los-desfiles

La Tribuna. (16 de Septiembre de 2017). Las mejores fotografías de palillonas en Tegucigalpa. Tegucigalpa, Honduras. Recuperado el 26 de Septiembre de 2017, de http://www.latribuna.hn/2017/09/16/las-mejores-fotografias-palillonas-tegucigalpa/

La Tribuna. (17 de Septiembre de 2017). Bellas palillonas visitan La Tribuna. Tegucigalpa, Honduras. Recuperado el 26 de Septiembre de 2017, de http://www.latribuna.hn/2017/09/17/bellas-palillonas-visitan-la-tribuna/

Nikken, P. (1994). Instituto de Derechos humanos. Recuperado el 9 de Octubre de 2017, de Estudios Básicos de Derechos Humanos: http://www.derechoshumanos.unlp.edu.ar/assets/files/documentos/el-concepto-dederechos-humanos.pdf

Organización de Estados Americanos (OEA). 2013. Convención de Belém do Pará.

Que Rebane Catracho. (2017). 15 Palillonas que te haran suspirar! Tegucigalpa, Honduras. Recuperado el 26 de Septiembre de 2017, de http://querebanecatracho.blogspot.com/2015/09/15-palillonas-que-te-haransuspirar.html

Radio America. (16 de Septiembre de 2017). La bella palillona de Danlí que impacta a Honduras. Tegucigalpa, Honduras. Recuperado el 27 de Septiembre de 2017, de http://radioamericahn.net/palillona-danli-honduras/

Torres, Luisa y Jiménez, Antonio. (2017). Enseñemos a discriminar estereotipos sexistas en la televisión. Revista científica iberoamericana de comunicación y educación, 2(25), 111. 
Talleres por la Igualdad. (2017). Recuperado el 26 de Septiembre de 2017, de http://www.cdp.udl.cat/tallers/index.php/es/glosario/item/92-cosificacion-de-la-mujer

Vota: ¿Quién es la palillona más bella de Honduras este 2016? (16 de Septiembre de 2016). El Heraldo. Recuperado el Septiembre de 25 de 2017, de http://www.elheraldo.hn/entretenimiento/1000191-466/vota-qui\%C3\%A9n-es-lapalillona-m\%C3\%A1s-bella-de-honduras-este-2016

Aguirre Concheso, M. J. (2013). Material Informativo y Educativo para jovenes adolescentes con trastornos alimenticios como anorexia y bulimia de la clinica de trasntornos alimenticios de la Licd. Brigitte Aquín. Guatemaña. Recuperado el 10 de Octubre de 2017, de http://glifos.unis.edu.gt/digital/tesis/2013/46000.pdf

Telesur. (24 de Julio de 2017). 187 mujeres asesinadas en Honduras en primer semestre de 2017. Recuperado el 10 de Octubre de 2017, de https://www.telesurtv.net/news/187mujeres-asesinadas-en-Honduras-en-primer-semestre-de-2017-20170724-0041.html

Observatorio de Igualdad de Género CEPAL. (15 de Julio de 2017). Observatorio de Igualdad de Género de América Latina y el Caribe. Obtenido de https://oig.cepal.org/es

UNICEF. (1989). Convención del niño. PDF. Recuperado el 25 de Septiembre de 2017, de http://www.un.org/es/events/childrenday/pdf/derechos.pdf

ONU. (2010). Convención sobre la eliminación de todas las formas de discriminación contra la mujer. 